\title{
Evaluation for Low Temperature Performance of SBS Modified Asphalt by Dynamic Shear Rheometer Method
}

\author{
Tao Wang ${ }^{1}$, Xuelei Wei ${ }^{1}$, De Zhang ${ }^{2}$, Hai Shi ${ }^{1, *}$ and Zhiqiang Cheng ${ }^{2,3, *}$ \\ 1 Department of Highway and Railway Engineering, School of Civil Engineering, Beijing Jiaotong University, \\ Beijing 100044, China; wangtao1@bjtu.edu.cn (T.W.); weixuelei@126.com (X.W.) \\ 2 Shanghai Road and Bridge (Group) Co., Ltd., Shanghai 200433, China; dez2021@163.com \\ 3 The Key Laboratory of Road and Traffic Engineering, Ministry of Education, Tongji University, Shanghai \\ 201804, China \\ * Correspondence: shihai@bjtu.edu.cn (H.S.); CR1903@tongji.edu.cn (Z.C.)
}

Citation: Wang, T.; Wei, X.; Zhang, D.; Shi, H.; Cheng, Z. Evaluation for Low Temperature Performance of SBS Modified Asphalt by Dynamic Shear Rheometer Method. Buildings 2021, 11, 408. https://doi.org/10.3390/ buildings11090408

Academic Editors: Xi Jiang,

Pawel Polaczyk, Rui Xiao and Wei Hu

Received: 10 August 2021

Accepted: 11 September 2021

Published: 13 September 2021

Publisher's Note: MDPI stays neutral with regard to jurisdictional claims in published maps and institutional affiliations.

Copyright: (c) 2021 by the authors. Licensee MDPI, Basel, Switzerland. This article is an open access article distributed under the terms and conditions of the Creative Commons Attribution (CC BY) license (https:/ / creativecommons.org/licenses/by/ $4.0 /)$.

\begin{abstract}
Finding an alternative or supplementary test method to evaluating the low temperature performance of asphalt is an area of considerable interest. This paper tries to explore the possibility of using the dynamic shear rheometer (DSR) method for assessing the low temperature properties of styrenebutadienestyrene (SBS) modified asphalt. In the study, 60/80 and 80/100 pen grade asphalt binders, named binder A-70, binder B-70 and binder C-90, are used to produce the SBS modified asphalt samples. After that, the low temperature performance of the asphalt binders is characterized by using bending beam rheometer (BBR) test. The results indicate that the low temperature performance of the different binders is related to the source of the binder. The low temperature performance of asphalt could be improved with the addition of the SBS. The DSR test is used to develop the complex modulus master curves for binders. Based on the principle of time-temperature conversion, the glass transition temperature of asphalt is calculated by the Williams-Landel-Ferry (WLF) equation. The glass transition temperatures $\left(\mathrm{T}_{\mathrm{g}}\right)$ of base asphalt and the SBS modified asphalt are determined by the viscoelastic parameters of the master curve and the WLF equation coefficients based on the time-temperature superposition principle. By establishing the relationship between the critical temperature and the $T_{g}$ of the asphalt binder, the effectiveness of the method established in this paper is verified. The advantage of this method is the ability to use the DSR test for the rapid evaluation of the low temperature performance of asphalt, which is able to reduce testing materials and save testing time as well. The glass transition temperature of the SBS modified asphalt is closely associated with aging degree, asphalt source and the SBS content.
\end{abstract}

Keywords: SBS modified asphalt; low temperature performance; BBR; DSR; glass transition temperature

\section{Introduction}

Since low temperature cracking remains one of the main failure modes of asphalt pavement in cold climate areas, significant attention is still being paid to the low temperature rheology of asphalt binders. In addition, while the performance of asphalt mixture is of secondary importance, the cracking resistance of asphalt pavement is mainly determined by the binder properties. Low temperature cracking usually occurs in extremely low temperature weather, within a few years after pavement construction, in general. This failure mode is visible on asphalt pavements because the binder could not deform when it is subject to temperature stress. When the stress exceeds the strength of the asphalt binder, transverse cracks could happen [1].

In order to reduce the failure frequency of low temperature cracking, it was necessary to improve the strength or stress relaxation capacity of the binder. The excellent low temperature performance of SBS modified asphalt has been widely recognized and widely used in pavement construction [2]. DSR is the key equipment in high and medium temperature PG systems. Bending beam rheometer (BBR) is the core equipment for low temperature 
measurement [3]. In the strategic highway research program (SHRP), DSR with parallel plate geometry was considered for low temperature PG systems, but was not selected because it was recognized that DSR measurements at temperatures below $5{ }^{\circ} \mathrm{C}$ suffer from compliance errors in the dynamic response when the typical film binders were used. Therefore, SHRP developed the BBR method to measure the low temperature rheological properties of asphalt binders (AASHTO T 313) [4]. A literature review showed that there are many articles about the low temperature rheology of asphalt [5]. However, the results of the study were subject to criticism if the low temperature properties of asphalt were measured using DSR. This was because the reliability of these test results was questionable. Due to the limitations of the instrument calibration, the limit temperature for DSR parallel plate measurements is approximately $5{ }^{\circ} \mathrm{C}[6]$.

With the progress of technology and related research $[7,8]$, it has been shown that the temperature of DSR measurement could be as low as $-40^{\circ} \mathrm{C}$. Although the BBR method has become the standard method for measuring low temperature performance, it has some shortcomings in operation. BBR takes a long time (about $3 \mathrm{~h}$ ) to make and test samples, and it requires a large amount of binder (about $15 \mathrm{~g}$ ) to manufacture each test sample, limiting, to a large extent, the low temperature testing of the binder obtained from field pavements [9]. With the passage of time, the field research of pavement performance monitoring became more and more important. However, it was very laborious and time consuming to extract a large amount of binder from the existing asphalt pavement for BBR tests [10]. In order to minimize this drawback, it would be valuable to use only a small amount of material for binder testing. Another disadvantage of the BBR method is that it is not reasonable to evaluate the low temperature cracking potential of binders because it only measures the stiffness (i.e., creep stiffness and relaxation rate) of a binder, rather than the fracture of a binder. Significant benefits are expected if an alternative method could be used to supplement (or replace) the existing BBR method used for the low temperature evaluation of binders, so as to improve the efficiency and accuracy of the grading evaluation procedure of binders [11,12]. In particular, if the method is based on DSR testing, only a single device is required to test the binder over the entire temperature range, which significantly reduces the test time and cost [13].

It is an urgent and important research task to evaluate the low temperature performance of asphalt materials. Asphalt materials are simple thermorheological materials. The macroscopic mechanical state is determined by the internal molecular movement state. The glass state transition temperature is a critical temperature in the process of the viscoelastic state changing with temperature $[14,15]$. Below the glass state transition temperature, the material is a brittle body with high modulus, and above the glass state transition temperature, it is in a viscoelastic state. Therefore, the glass transition temperature has rich physical and chemical significance, which can characterize the low temperature performance of asphalt materials [16]. The glass transition temperature could be used to characterize the low temperature performance of asphalt materials $[17,18]$. The ideal state is that the glass transition temperature is less than the minimum service temperature of asphalt material, so as to ensure its good deformation performance in the process of use, relax the internal accumulated stress, and avoid pavement cracking. In short, the lower the glass transition temperature, the better the low temperature performance of asphalt materials [19].

It is inconvenient to measure the glass transition temperature directly. The mechanical properties and many other physical properties, such as specific volume, the coefficient of expansion, specific heat capacity, thermal conductivity, density and dielectric constant of rheological materials change when they are in a glass state. Therefore, in principle, physical properties that undergo abrupt or discontinuous change during the glass transition process could be used to determine the glass transition temperature of a material [20].

Liu et al. presented an approach for analytically estimating the glass transition temperature using the viscoelastic parameters of master curves. A link between the glass transition temperature and the viscoelastic characteristic of asphalt binders was established. 
From the master curve, the reduced frequency corresponding to the peak of the loss modulus could be used to back calculate the glass transition temperature [21,22]. Kris used the master curve to determine the value of $\mathrm{T}_{\mathrm{g}}$ for asphalt binders. It was found that the glass transition temperature and enthalpy relaxation increased linearly with the logarithm of storage time, indicating that the properties of asphalt change isothermally. Meanwhile, it was found that the characteristic relaxation time increases with the increase in isothermal storage time, indicating that the ability of the adhesive to relax stress under isothermal conditions decreases with the passage of time [23]. Sun et al. proposed a new program to characterize the rheological properties of asphalt binders across the whole pavement service frequency and temperature range. The results showed that the combination of BBR and DSR data greatly expanded the scale of complex shear modulus. The corresponding linear viscoelastic (LVE) master curve could be incorporated into the existing asphalt concrete complex modulus prediction equation, for better pavement response analysis and performance evaluation [24].

So far, there is no recognized and reasonable test method for the glass transition temperature of asphalt and asphalt mixtures. With the popularization of dynamic mechanical properties research in the field of road structure and materials, a dynamic mechanical performance test for asphalt materials or asphalt mixtures has gradually become a norm. The glass transition temperature of the material could be calculated by using the time temperature conversion principle and WLF equation, which not only maximizes the benefits of the existing experimental data, but also provides an effective method to determine the glass transition temperature.

One of the objectives of this study was to find an alternative or complementary test means or analytical method for the determination of the low temperature properties of asphalt using DSR, which is currently performed by the BBR test. More specifically, by comparing the correlation of the results obtained by the two test methods, BBR method could be supplemented (or potentially replaced), based on the material parameters generated by the DSR test and analysis methods. Three asphalt preparations of binder modified asphalt were selected for testing, and, thus, general conclusions were drawn. The final results obtained could be used as a strong complement to the BBR tests. It is hoped that the scientific insights provided could help to understand the inner low temperature mechanism of the material, realize the convenience and rapidity of the low temperature testing of pavement materials, and materialize certain engineering value and economy as well.

\section{Materials and Methods}

\subsection{Materials}

Asphalt binders A70, B70 and C90, used in this study, were obtained from the same local oil company. The physical properties of base binders are shown in Table 1. Three kinds of base binder materials, from the same area, were blended with SBS to prepare SBS modified asphalt. The asphalt binder was produced in a shear mixer at a constant speed of $1000 \mathrm{rpm}$ at $170{ }^{\circ} \mathrm{C}$ for $2 \mathrm{~h}$, and then poured into a barrel for cooling. In particular, all asphalt binders were kept at the same heating time to avoid an aging effect from the original binders.

Table 1. Performance results of base binder.

\begin{tabular}{cccccc}
\hline Physical Properties & Binder A70 & Binder B70 & Binder C90 & Standard & Test Method \\
\hline Penetration $\left(25^{\circ} \mathrm{C}, 5 \mathrm{~s}, 100 \mathrm{~g}\right)(0.1 \mathrm{~mm})$ & 72.3 & 73.2 & 95.2 & $60-80$ & T0604 \\
Softening point $(\mathrm{R} \& \mathrm{~B}) /{ }^{\circ} \mathrm{C}$ & 47.8 & 48.3 & 47.4 & $\geq 46$ & T0606 \\
Viscosity $\left(60^{\circ} \mathrm{C}\right) / \mathrm{Pa} \cdot \mathrm{s}$ & 187 & 194 & 184 & $\geq 180$ & T0620 \\
Ductility $\left(10^{\circ} \mathrm{C}, 5 \mathrm{~cm} / \mathrm{min}\right) / \mathrm{cm}$ & 39 & 34 & 45 & $\geq 20$ & T0605 \\
\hline
\end{tabular}




\subsection{Sample Preparations and Test Methodologies}

\subsubsection{Bending Beam Rheometer (BBR) Test}

To prepare the BBR sample, a test sample of approximately $25 \mathrm{~g}$ was heated in a small container until it flowed. Then, the heated binder was poured into a mold and allowed to cool for $30 \mathrm{~min}$. After the binder sample cooled to room temperature, the excess binder material on the top of the mold was carefully trimmed, to leave a smooth surface on the top, and then refrigerated for $20 \mathrm{~min}$. Afterwards, the metal parts were carefully released from the mold to obtain a sample. The trabecular sample size (length $\times$ width $\times$ depth) was $12.5 \times 12.5 \times 6.5 \mathrm{~mm}$. The whole BBR sample was prepared according to the method described in specification T 0627-2011 (or ASTM 6648-08) [25,26].

Different types of samples in unaged, RTFO and PAV states were tested using a bending beam rheometer. The three point bending test was carried out on the beam sample by applying a load to the mid span of the beam. Temperature control was achieved by an external temperature control unit, and a cooling medium in the instrument box was used to obtain a uniform temperature field. In the three point bending test, a contact load of $35 \pm 10 \mathrm{mN}$ was applied to the midspan of the beam, followed by a constant test load of $980 \pm 50 \mathrm{mN}$. The deflection, with time, at the bottom midspan was measured during the application of the test load. The stiffness $S(t)$ of the beam as a function of time could be estimated by Equation (1) [27].

$$
S(t)=\frac{P L^{3}}{4 b h^{3} \Delta(t)}
$$

where $P$ is the test load, $L$ is the distance between support points, $b$ and $h$ are the width and height of beam, respectively, and $\Delta(t)$ is the midspan deflection of test time, $t$. According to the low temperature standard of NCHRP-PG measured in SHRP, the stiffness modulus is $S(T=60 \mathrm{~s}) \leq 300 \mathrm{MPa}$, and creep slope is $m(T=60 \mathrm{~s}) \geq 0.3$, where $m(T)$ is the slope of $\log (S(t))$ to $\log (t)$.

The larger $S$ value indicated that the binder was more brittle; the specimen was more prone to fracture at low temperature. A larger creep rate, $m$, indicated that the stiffness modulus of asphalt changed faster with time, indicating that the asphalt stress relaxation capacity was stronger, which could effectively alleviate the emergence of low temperature pavement cracking.

\subsubsection{Dynamic Shear Rheometer Temperature-Frequency Sweep Tests}

The low temperature rheological behavior of each binder was obtained by DSR with $8 \mathrm{~mm}$ and $25 \mathrm{~mm}$ parallel metal plates. For each binder, the material response dependent on temperature and loading frequency was identified by plotting the linear viscoelastic master curves of oscillatory response, such as dynamic modulus $\left(\left|G^{*}\right|\right)$ and phase angle ( $\delta$ ). The viscoelastic response of viscoelastic material is expressed by linear viscoelastic theory. The parameters of a viscoelastic material are obtained by fitting the viscoelastic model with the actual principal curve.

Compared with the sample preparation of BBR, the sample preparation using $8 \mathrm{~mm}$ or $25 \mathrm{~mm}$ parallel plates for the DSR test was relatively easy, simple and time saving. This was one of the main reasons why DSR has been more important than BBR in the low temperature characterization of binders in recent years. For the DSR binder samples, the binder was heated until the sample could flow freely, and then poured into the corresponding mold to cool for later use.

The accurate preparation of DSR samples was the key to obtaining representative and repeatable results. If the sample was not placed or trimmed properly, there might be large errors in estimating material properties. Each sample was tested twice to obtain its rheological response over a wide temperature range.

The test temperature range of base asphalt and SBS modified asphalt was $0-80^{\circ} \mathrm{C}$, the temperature gradient was $10^{\circ} \mathrm{C}$, and the frequency was $0.1-25 \mathrm{~Hz}$. In order to avoid too small a distance between parallel plates, which could lead to excessive sample restraint and could be out of the linear elastic range of the sample, it was necessary to select the rotor size 
of the sample and the test spacing of the parallel plate reasonably. The specific parameters of each sample are shown in Table 2. In order to ensure that the sample frequency scanning was always in the linear elastic range, the appropriate strain value was selected through the strain amplitude scanning test. Due to the large number and complex types of test samples, it was impossible to scan each sample at first. Since the peak strain of the sample would decrease with the increase in frequency and the decrease in temperature, the peak strain value was determined by considering the most unfavorable test condition, $0{ }^{\circ} \mathrm{C}$, and a frequency of $25 \mathrm{~Hz}$. Since the rheological indexes are all based on the online viscoelasticity, when the complex shear modulus decreases to $95 \%$ of the initial value, the strain at this time could be regarded as the peak strain in the range of linear viscoelasticity. The strain value of asphalt was determined to be $0.1 \%$. Then, frequency scanning tests were carried out on the samples at different temperatures, to obtain the data related to the construction of the main curve.

Table 2. Test parameters of frequency scanning test.

\begin{tabular}{|c|c|c|c|}
\hline Material Types & Temperature $/{ }^{\circ} \mathrm{C}$ & Frequency/Hz & Geometry/mm \\
\hline $\begin{array}{c}\text { Base Binder } \\
\text { (unaged, RTFO and PAV) }\end{array}$ & 0-80@10 & $0.1-25$ & $\begin{array}{c}\varphi 8 \mathrm{~mm} @ 1 \mathrm{~mm}\left(0-40^{\circ} \mathrm{C}\right) \\
\varphi 25 \mathrm{~mm} @ 1 \mathrm{~mm}\left(50-80^{\circ} \mathrm{C}\right)\end{array}$ \\
\hline $\begin{array}{l}\text { SBS modified binder } \\
\text { (OB, RTFO and PAV) }\end{array}$ & 0-80@10 & $0.1-25$ & $\begin{array}{c}\varphi 8 \mathrm{~mm} @ 2 \mathrm{~mm}\left(0-40^{\circ} \mathrm{C}\right) \\
\varphi 25 \mathrm{~mm} @ 2 \mathrm{~mm}\left(50-80^{\circ} \mathrm{C}\right)\end{array}$ \\
\hline
\end{tabular}

\subsubsection{Method of Determining Complex Modulus and Phase Angle Master Curves}

The low temperature material response of each binder was evaluated by frequency sweep test to obtain nondestructive linear viscoelastic properties related to the material. Then, using the sweep frequency data and the principle of time temperature superposition, the main curve at a specific reference temperature was obtained.

\section{Time-Temperature Equivalence Principle}

The main modulus curve could be obtained by translating the modulus curves at different temperatures through the time-temperature displacement factor to the modulus curve at the reference temperature. The effect of temperature on the complex modulus was only to shift the modulus curve at different temperatures, with its shape remaining unchanged. According to the time-temperature equivalence principle, the influence of temperature and frequency (loading time) on asphalt material could be transformed into the effect of reduced frequency through time-temperature displacement factor. The reduced frequency was obtained from Formula (2):

$$
\omega_{r}=\omega \times \alpha_{T}
$$

where $\omega_{r}$ was the reduced frequency; $\omega$ was the frequency; $\alpha_{T}$ was the time-temperature displacement factor.

In this study, the time temperature displacement factor was obtained by WilliamsLandel-Ferry (WLF) equation, as shown in Equation (3):

$$
\lg \left(\alpha_{T}\right)=\frac{-C_{1}\left(T-T_{0}\right)}{C_{2}+T-T_{0}}
$$

where $\lg \left(\alpha_{T}\right)$ is the horizontal shift factor corresponding to the temperature, $T ; T_{0}$ is the reference temperature; and $C_{1}$ and $C_{2}$ are the empirical parameters, with their values changing with the reference temperature. 
For a given reference temperature, the magnitude of the horizontal shift of the loading frequency is called the shift factor. The relationship between the shift factor, $\alpha(T)$, and the reduced frequency, $f_{r}$, is shown in Equation (4)

$$
f_{r}=f \times \alpha(T)
$$

where $f_{r}$ is the reduced frequency, measured in $\mathrm{Hz} ; f$ is the loading frequency, measured in $\mathrm{Hz}$; and $\alpha(T)$ is the shift factor.

If the logarithm of both sides of the above formula is taken, the reduced frequency is equal to [28]:

$$
\log f_{r}=\log f+\log \frac{-C_{1}\left(T-T_{0}\right)}{C_{2}+T-T_{0}}
$$

\section{Complex Modulus Master Curve Model}

According to the relevant research, the linear viscoelastic characteristics of asphalt cement can be well characterized by constructing the main curve. Due to the limitation of test conditions, it was difficult to obtain the mechanical properties of the asphalt materials under the condition of short time (high frequency), and it was also difficult to observe the asphalt materials for a long time. The influence of frequency (loading time) and temperature on the asphalt materials could be transformed into a reduction of frequency by means of time-temperature shift factor by constructing the main curve. In this paper, the viscoelastic behavior of SBS modified asphalt in wide temperature range and wide frequency domain was studied by standard logistic rheological model, as shown in Equation (6) [24]:

$$
\log \left|G^{*}\right|=\theta+\frac{\alpha-\theta}{1+e^{\beta+\gamma \cdot \log f_{r}}}
$$

where $G^{*}$ is complex shear modulus $(\mathrm{kPa}), \theta$ is equilibrium modulus, $\alpha$ is glassy modulus, $f_{\mathrm{r}}$ is reduced frequency, and $\beta$ and $\gamma$ are two shape parameters.

\subsubsection{Derivation of the Formula for the Glass Transition Temperature}

According to Equation (3), two different temperatures, $T_{1}$ and $T_{2}$, were selected in the determination of temperature conditions to derive $T_{\mathrm{g}}$ [29], then

$$
\begin{aligned}
& \lg \left(\alpha_{T 1}\right)=\frac{-C_{1}\left(T_{1}-T_{\mathrm{g}}\right)}{C_{2}+T_{1}-T_{g}} \\
& \lg \left(\alpha_{T 2}\right)=\frac{-C_{1}\left(T_{2}-T_{\mathrm{g}}\right)}{C_{2}+T_{2}-T_{g}}
\end{aligned}
$$

where $T_{1} \neq T_{2} ; \alpha_{T 1}$ and $\alpha_{T 2}$ are horizontal shift factors of $T_{1}$ and $T_{2}$, respectively.

If $T_{1}$ is the reference temperature, the logarithm difference $\lg \left(\alpha_{T 2}^{\prime}\right)$ of shift factor at temperature $T_{2}$ relative to $T_{1}$ could be obtained by formulas (7) and (8)

$$
\lg \left(\alpha_{T 2}^{\prime}\right)=\lg \left(\alpha_{T 2}\right)-\lg \left(\alpha_{T 1}\right)
$$

Derived from Equation (9)

$$
\lg \left(\alpha_{T 2}^{\prime}\right)=C_{1} \times C_{2} \frac{T_{1}-T_{2}}{\left(C_{2}+T_{2}-T_{g}\right)\left(C_{2}+T_{1}-T_{\mathrm{g}}\right)}
$$

In the formula, there were only three unknowns, $C_{1}, C_{2}$ and $T_{\mathrm{g}}$. According to the previous studies, if $T_{\mathrm{g}}$ of a polymer is taken as reference temperature, the universal constants of an amorphous polymer are $C_{1}=17.44, C_{2}=51.6$. By means of least square nonlinear fitting with Excel software, the $T_{\mathrm{g}}$, which was not covered by test temperature, can be calculated. 


\section{Results and Discussion}

\subsection{Analysis of BBR Test Results}

The low temperature performance requirements of the binder, with reference to the Superpave specification, were a stiffness of less than $300 \mathrm{MPa}$ and an m-value greater than 0.30. The temperature dependence of the stiffness values of the A70 base asphalt and SBS modified asphalt, after PAV aging, are shown in Figure 1a. As shown in Figure 1a, the stiffness value of the SBS modified binder decreased significantly in a lower temperature condition. This could be explained by the loss of the viscosity of the asphalt binder at a low temperature, so the binder appeared to change from a liquid state at high temperatures, to a solid state at low temperatures. The addition of SBS was effective in reducing the modulus increase of the asphalt at low temperatures, which had a positive impact on the low temperature performance of asphalt.

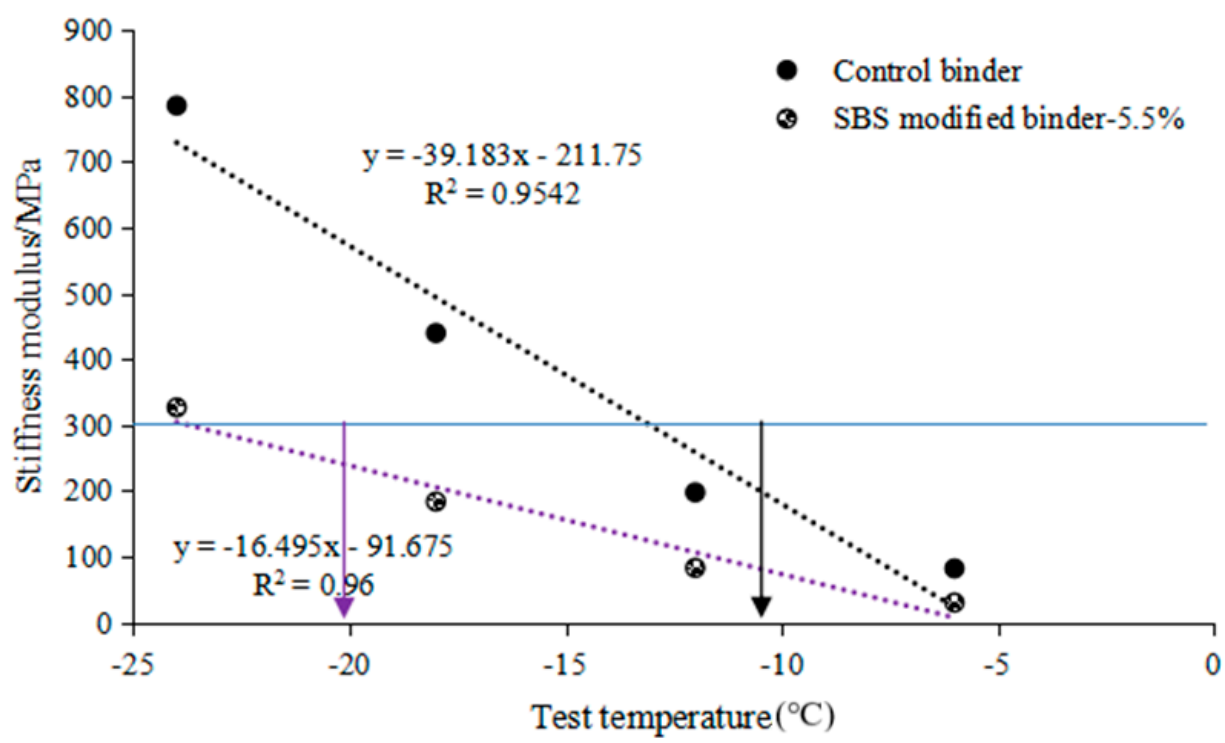

(a)

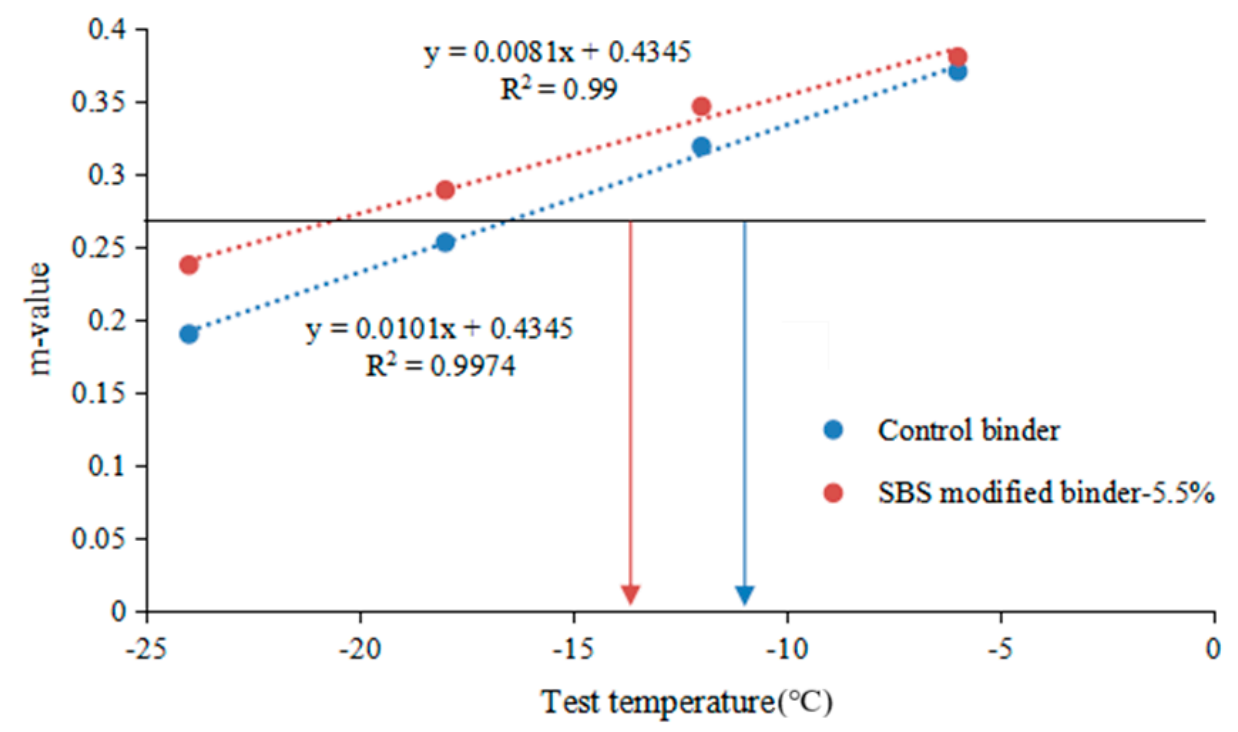

(b)

Figure 1. Stiffness values and m-values of SBS modified binders produced with binder source A70 versus test temperature: (a) Stiffness values; (b) m-values. 
Figure $1 \mathrm{~b}$ shows the trend of m-values of the A70 base asphalt and SBS modified asphalt with test temperature. As shown in Figure 1b, there was an opposite trend in the $\mathrm{m}$-value with test temperature when the $\mathrm{m}$-value increased at higher temperatures compared to the stiffness value. The critical temperature of the base binder, determined by the $\mathrm{m}$ value in this study, was $-9.5^{\circ} \mathrm{C}$. The critical temperature of the SBS modified binder with $5.5 \% \mathrm{SBS}$ was $-12.3^{\circ} \mathrm{C}$. It can be seen from the results that the low temperature relaxation ability of asphalt was improved by adding SBS. The critical temperature of the other SBS modified asphalt samples could also be determined by this method.

The critical temperature of the binders was determined by fulfilling the requirement for the stiffness value and the $\mathrm{m}$-value at the same time. Therefore, the higher one of these two temperatures, the stiffness value and the m-value, was chosen to determine the low critical temperature of the various binders. Based on the stiffness value and $\mathrm{m}$-value requirements, the minimum low temperature rating of each modified binder was determined, as described above, as shown in Table 3.

Table 3. Minimum low temperature determination results of SBS binders.

\begin{tabular}{cccc}
\hline Minimum Temperature & Stiffness & m-Value & $\begin{array}{c}\text { Low Temperature } \\
\text { Determination }\end{array}$ \\
\hline Control-A70 & -11.4 & -9.5 & $-19.5=-9.5-10$ \\
\hline 4.5 SBS-A70 & -15.6 & -10.2 & $-20.2=-10.2-10$ \\
\hline 5.0 SBS-A70 & -18.4 & -11.3 & $-21.3=-11.3-10$ \\
\hline $5.5 S B S-A 70$ & -22.0 & -12.2 & $-22.2=-12.2-10$ \\
\hline Control-A70 & -12.1 & -11.1 & $-21.1=-11.1-10$ \\
\hline 4.5 SBS-B70 & -13.1 & -11.4 & $-21.4=-11.4-10$ \\
\hline $5.0 S B S-B 70$ & -18.2 & -11.6 & $-21.6=-11.6-10$ \\
\hline $5.5 S B S-B 70$ & -21.8 & -13.3 & $-23.3=-13.3-10$ \\
\hline Control-C90 & -14.9 & -12.7 & $-22.7=-12.7-10$ \\
\hline 4.5 SBS-C90 & -17.9 & -13.2 & $-23.2=-13.2-10$ \\
\hline $5.0 S B S-C 90$ & -1.2 & -15.1 & $-25.1=-15.1-10$ \\
\hline $5.5 S B S-C 90$ & 27.1 & -21.7 & $-31.7=-21.7-10$ \\
\hline
\end{tabular}

In Figure 2, it is shown that there was a significant difference between the SBS modified binders produced using three different sources of virgin asphalt. SBS modified asphalt produced from the $\mathrm{C} 90$ binder had a lower low temperature criticality than the A70 and B70 binders. The results indicate that high grade asphalt has a beneficial effect on the low temperature performance, and the low temperature performance of different binders was related to the binder source.

\subsection{Analysis of $T_{g}$ Calculation Results of SBS Modified Asphalt Based on Master Curve Test}

It has gradually become the norm to conduct dynamic mechanical performance tests on asphalt materials. Using these kinetic test data for analysis, and calculating the glass transition temperature of the material through the time-temperature superposition principle (TTSP) and the WLF equation, not only maximized the benefits of the existing test data, but also provided an effective method for solving the glass transition temperature. The master curve of the complex modulus constructed in combination with the dynamic shear test was calculated based on the principle of time-temperature conversion, and the glass transition temperature of the asphalt material was calculated using the WLF equation, as shown in Figure 3. On the other hand, using the changing characteristics of the asphalt components to explore the relationship between them and the glass transition temperature exhibited some useful discussions on the microscopic composition change rules behind the viscoelastic behavior of asphalt. Therefore, based on the frequency scanning test results of 
the base binder and the SBS modified asphalt at $0,10,20,30,40,50,60,70$ and $80^{\circ} \mathrm{C}$, the viscoelastic parameter master curve and its displacement factor, for the A70 SBS modified asphalt under a PAV aging condition, were obtained, according to the time-temperature equivalent principle based on the reference temperature of $20^{\circ} \mathrm{C}$. The same results could be obtained for the other materials.

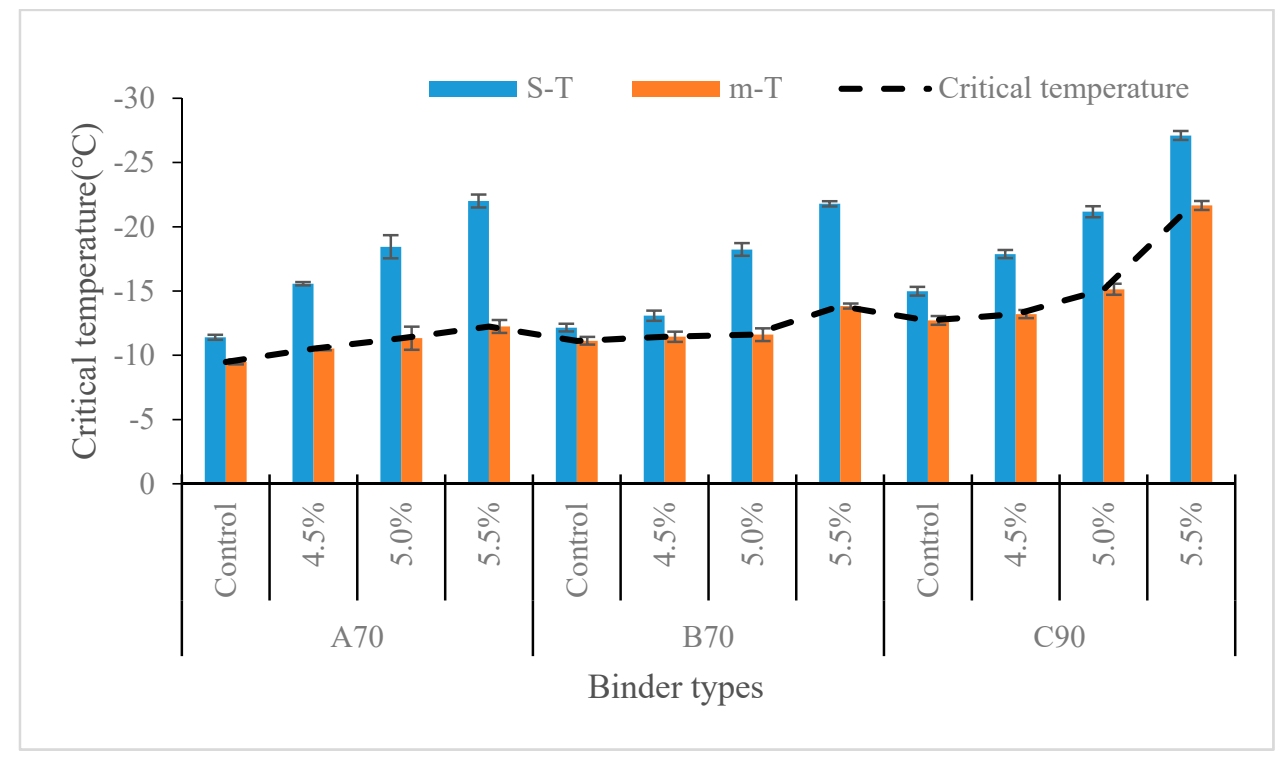

Figure 2. Minimum low temperatures of various binders. Note: S-T means stiffness modulus temperature; $\mathrm{m}$-T means $\mathrm{m}$ value temperature.

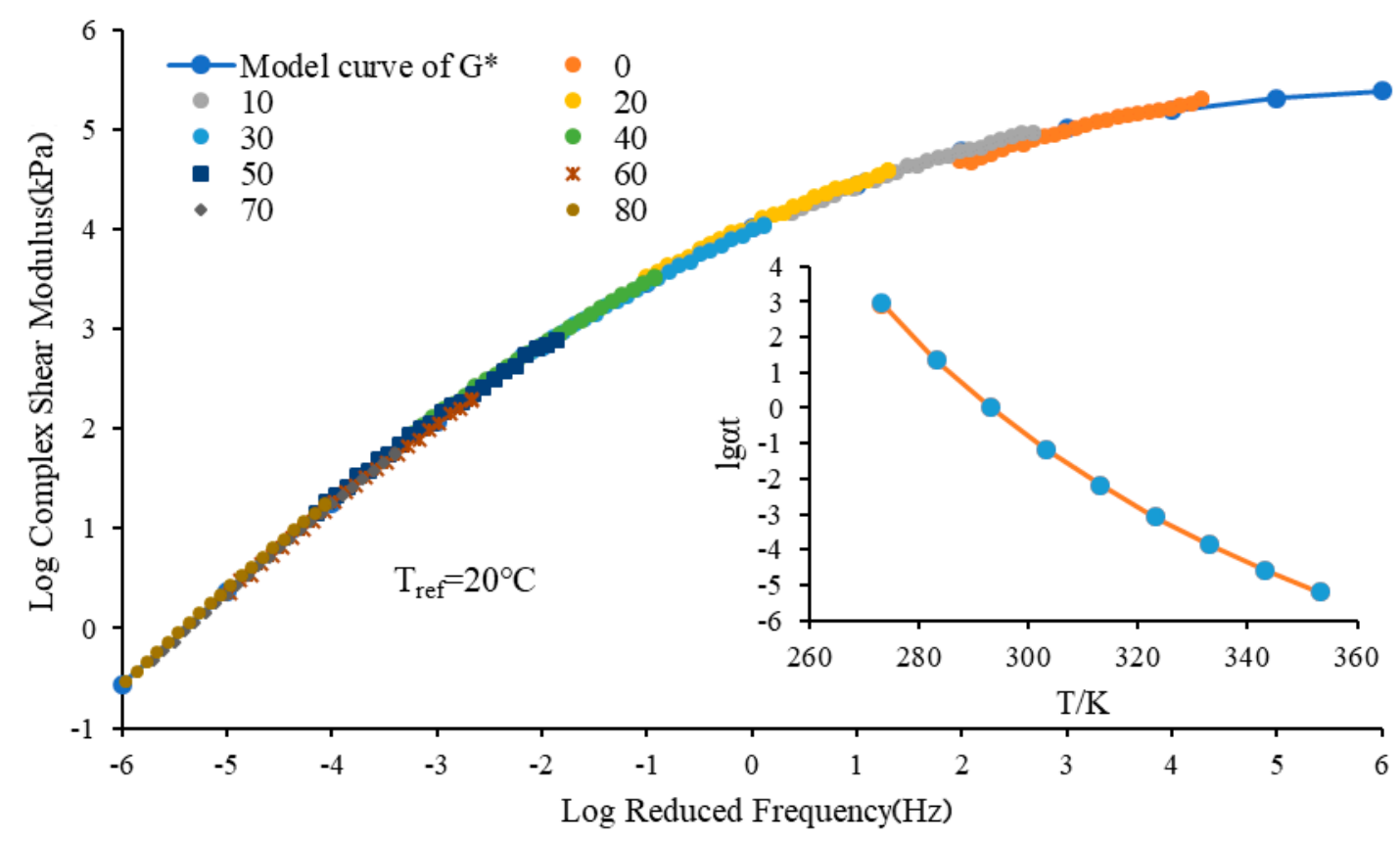

Figure 3. Complex shear modulus master curve and displacement factor of A70 SBS modified asphalt at 293.15 K.

According to the principle of time-temperature equivalence, the shift factor at a reference temperature of $20^{\circ} \mathrm{C}$ was obtained. The glass transition temperature of the material was obtained by nonlinear fitting of least square method with Excel software, using Formula (10). As shown in the Figure 4, $262.62 \mathrm{~K}$ was the glass transition temperature of the material, and the fitting effect was good. According to the same method, the glass transition temperature of the other asphalts could be obtained. 


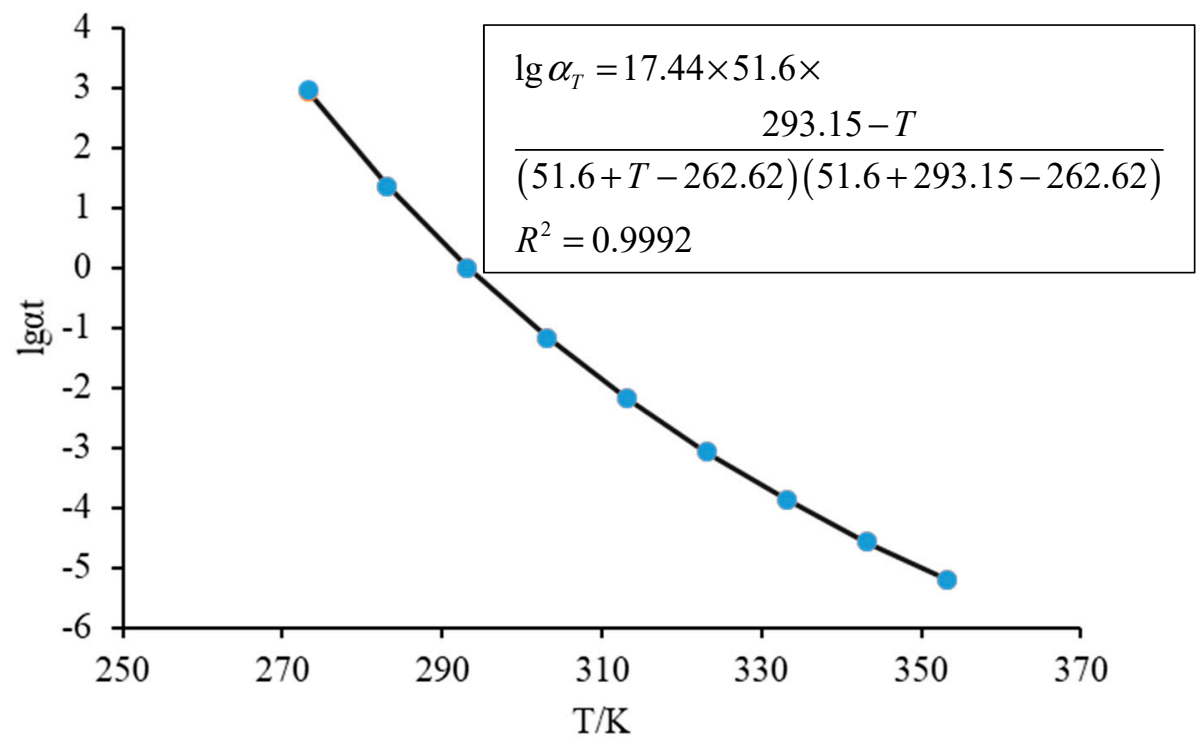

Figure 4. Fitting results of $\mathrm{T}_{g}$ of SBS modified asphalt.

The $\mathrm{T}_{g}$ of the base asphalt and SBS modified asphalt was obtained by the above method. Taking the SBS modified asphalt with different grades in a PAV state, the $\mathrm{T}_{g}$ of the SBS modified asphalt decreased with the increase in SBS content, as shown in Figure 5. That is to say, the low temperature performance of the SBS modified asphalt was improved by adding the SBS. This shows that SBS could improve the low temperature performance of asphalt materials.

\subsection{Validation of Glass Transition Temperature Results}

The glass transition temperature calculated by the dynamic mechanical test data could reveal the low temperature performance of the SBS modified asphalt. The glass transition temperature not only had a clearly physical significance, but also could characterize the difference in low temperature performances between different base asphalt and SBS modified asphalts. In order to verify this result, it was feasible to use the glass transition temperature to evaluate the low temperature performance of asphalt materials, which was then validated in conjunction with the BBR test results in the paper.

\subsubsection{The Glass Transition Temperatures of Different Asphalt Binder Sources}

It can be seen from Figure 6 that the correlation coefficient $r=0.987$, between the critical temperature and its $\mathrm{T}_{g}$, of the A70 SBS modified asphalt is greater than 0.950 (the confidence degree is $95 \%$, and the degree of freedom is 2). The correlation coefficient $\mathrm{r}=0.892$, between the critical temperature and its $\mathrm{T}_{g}$, of the B70 SBS modified asphalt was less than 0.950 (the confidence degree is $95 \%$, the degree of freedom is 2), and the correlation coefficient $\mathrm{r}=0.993$, between the critical temperature and its $\mathrm{T}_{g}$, of the C90 SBS modified asphalt was greater than 0.950 (the confidence degree is $95 \%$, the degree of freedom is 2). The results indicate that there is a significant correlation between the two indicators. Therefore, it is reasonable to use $\mathrm{T}_{g}$, as calculated by DSR data, to evaluate the low temperature performance of SBS modified asphalt.

In order to further illustrate the relationship between critical temperature and the $\mathrm{T}_{g}$ of SBS asphalt modified with different asphalt sources, the SBS asphalt modified with different asphalt sources should be analyzed. It can be seen from Figure 7 that the correlation coefficient, between the critical temperature and $\mathrm{T}_{g}$ of the three kinds of SBS modified asphalt, was 0.93 , which is greater than 0.632 (the confidence degree is $95 \%$, and the degree of freedom was 10), indicating that there was a significant correlation between the critical temperature and $\mathrm{T}_{g}$ of the three kinds of SBS modified asphalt. Moreover, it could be seen intuitively that the low temperature performance of the C90 SBS modified 
asphalt was better than that of A70 and B70 SBS modified asphalt. It can be seen from Figure $7 \mathrm{~b}$ that, with the increase of SBS content, the critical temperature and $\mathrm{T}_{g}$ of the SBS modified asphalt obviously decreased. Therefore, the influence of the SBS content on its low temperature performance was very significant, and the SBS asphalt modified by adding $5.5 \%$ of SBS content had the best low temperature performance. As the glass transition temperature had a clearly physical significance, it could characterize the difference in lowtemperature performance between different asphalt sources and different SBS contents, and the evaluation results had a significant correlation with the critical temperature of the low temperature creep of the SBS modified asphalts (the confidence level is $95 \%$ ). As a result, the data obtained by DSR experiments to calculate the glass transition temperature could be evaluated for the low temperature properties of the SBS modified asphalts. The method could not only reduce the workload of low temperature performance tests, it also provided strong and complementary evidence to evaluate the low temperature performance of asphalt materials.

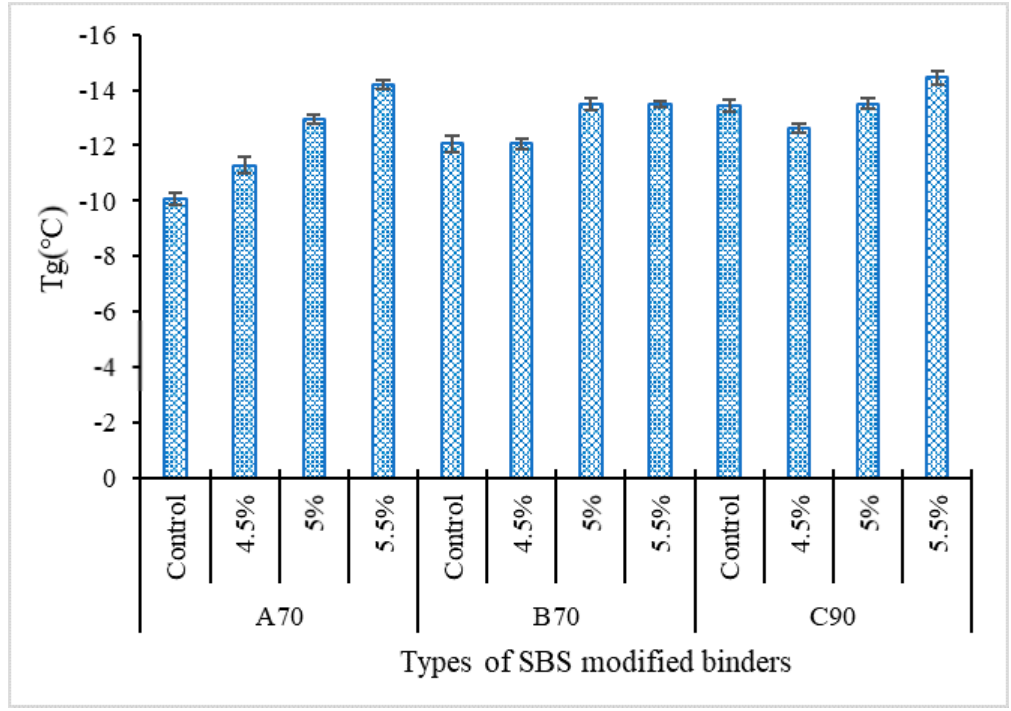

(a)

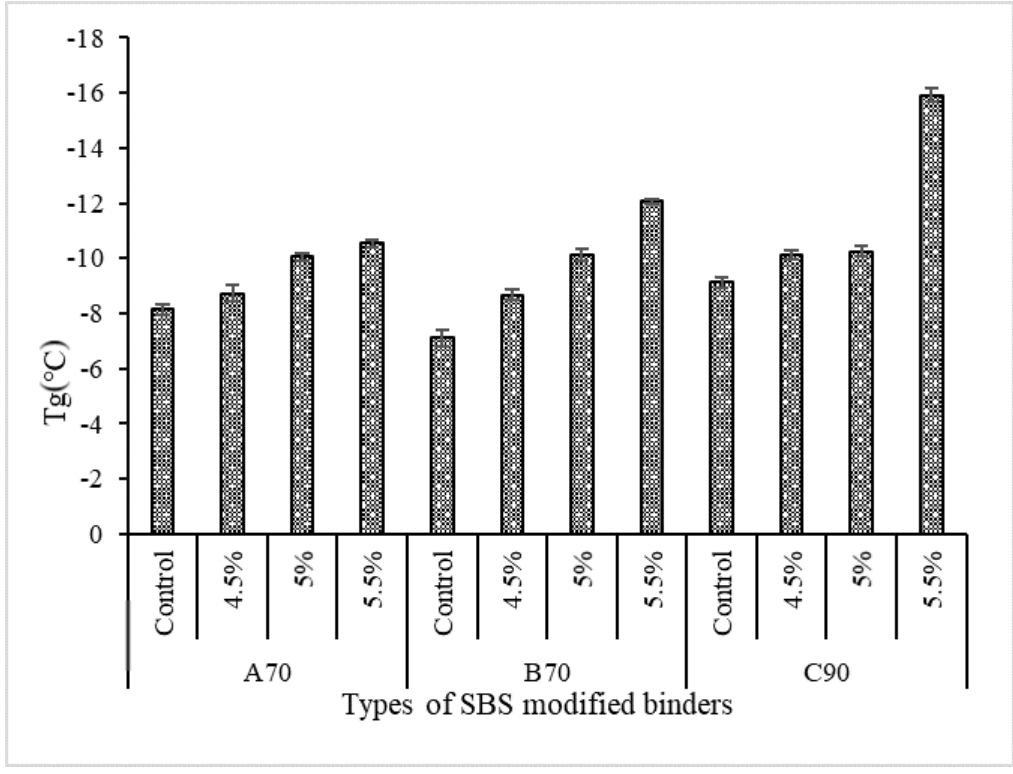

(b)

Figure 5. Fitting results of different SBS modified asphalts: (a) unaged state; (b) PAV state. 


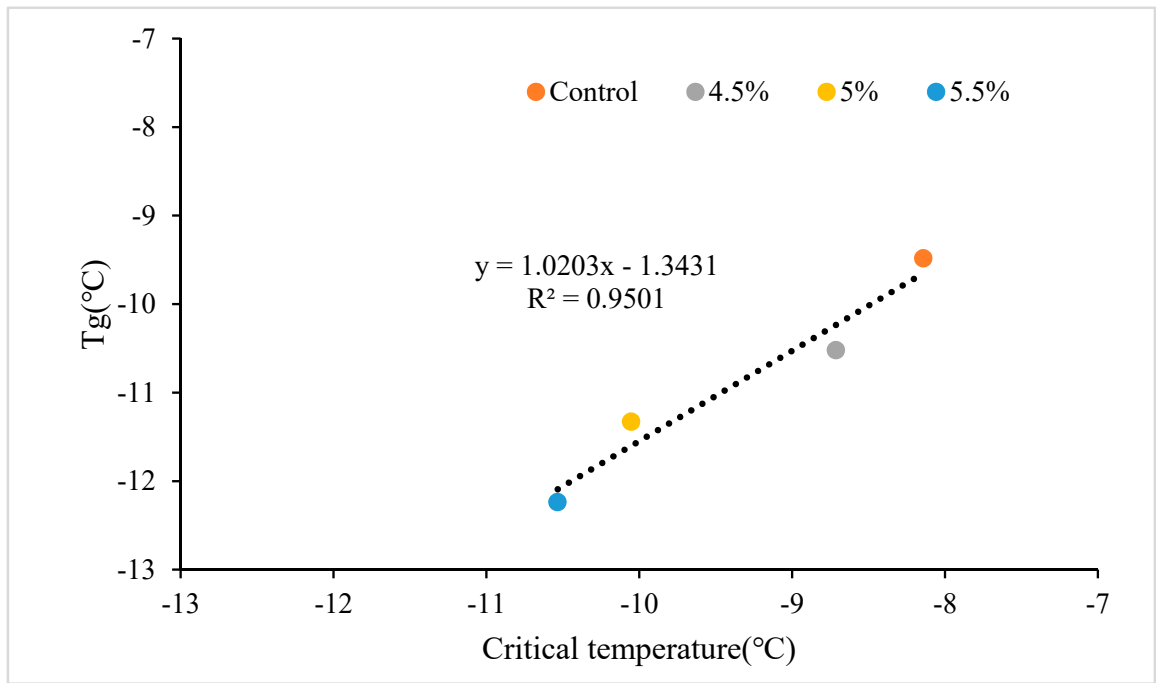

(a)

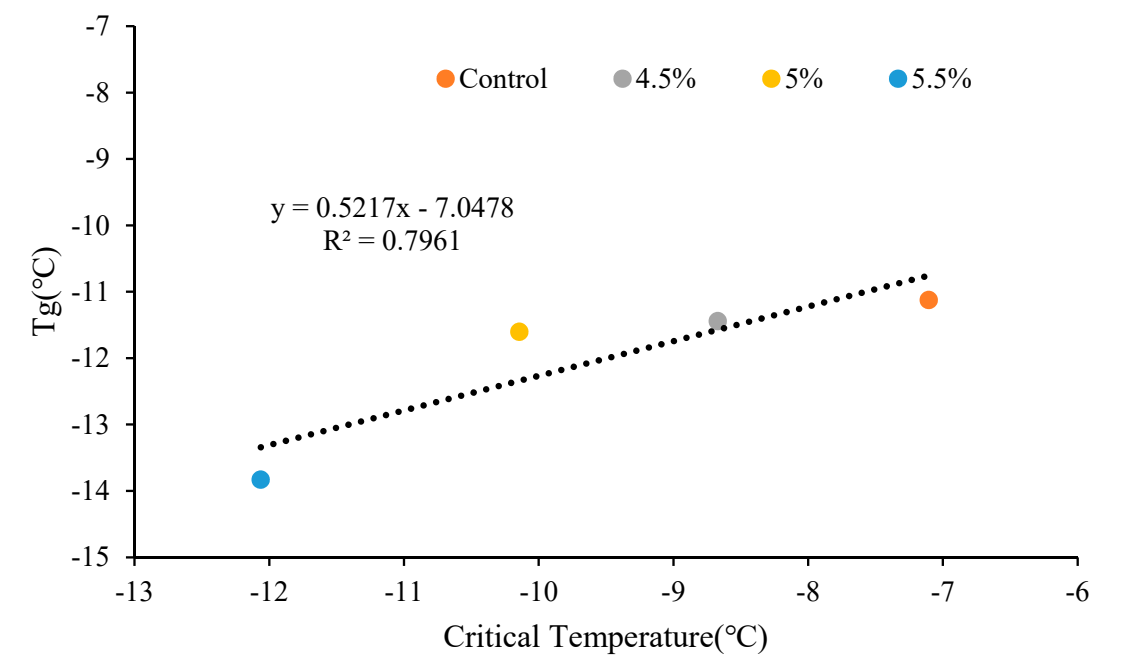

(b)

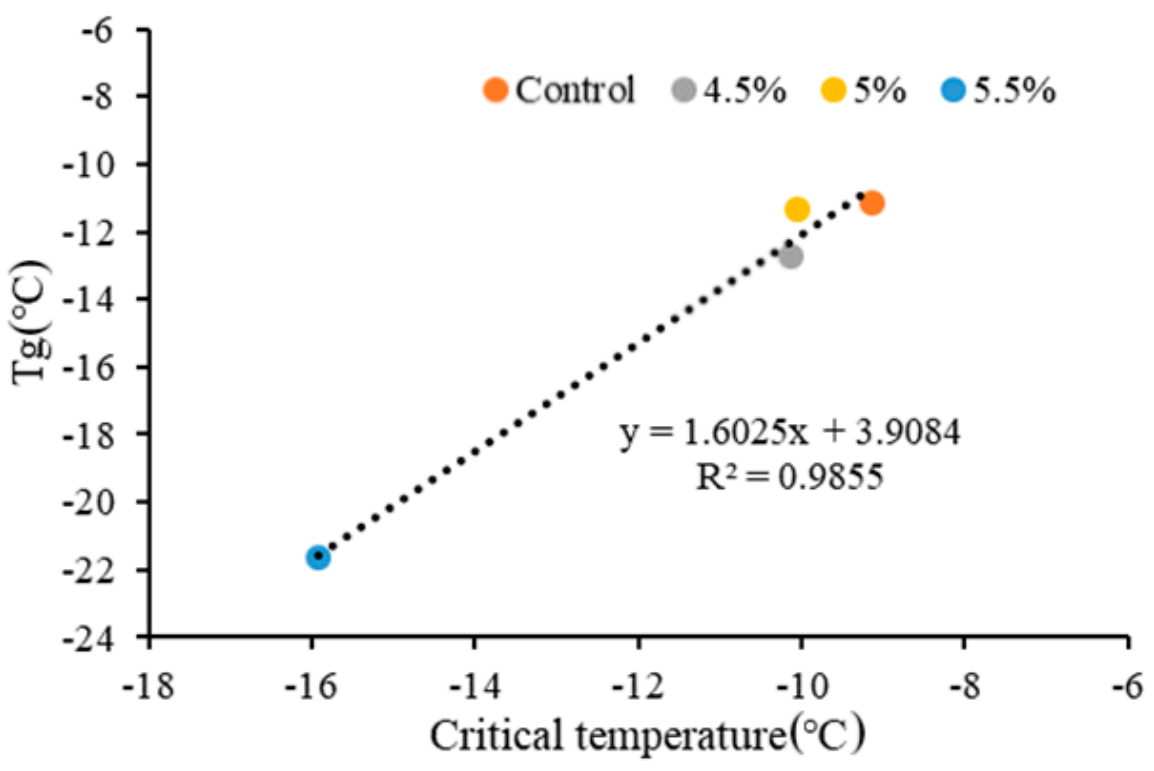

(c)

Figure 6. The relationship between critical temperature and $\mathrm{T}_{g}$ (a) A70, (b) B70, (c) C90. 


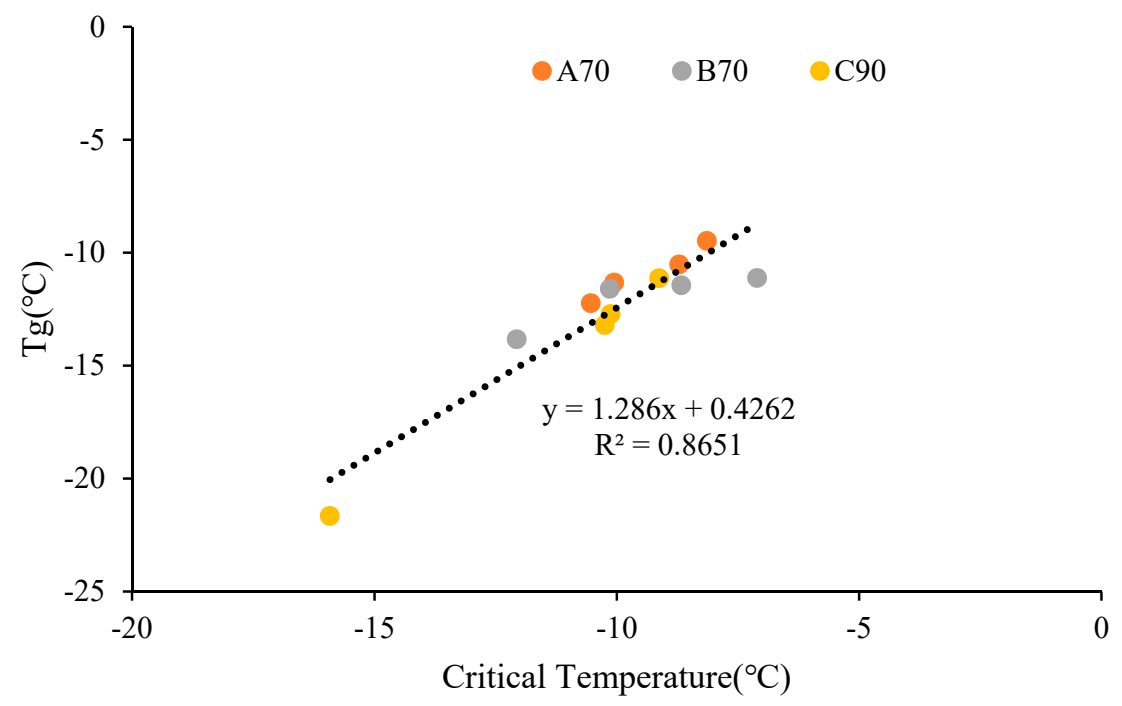

(a)

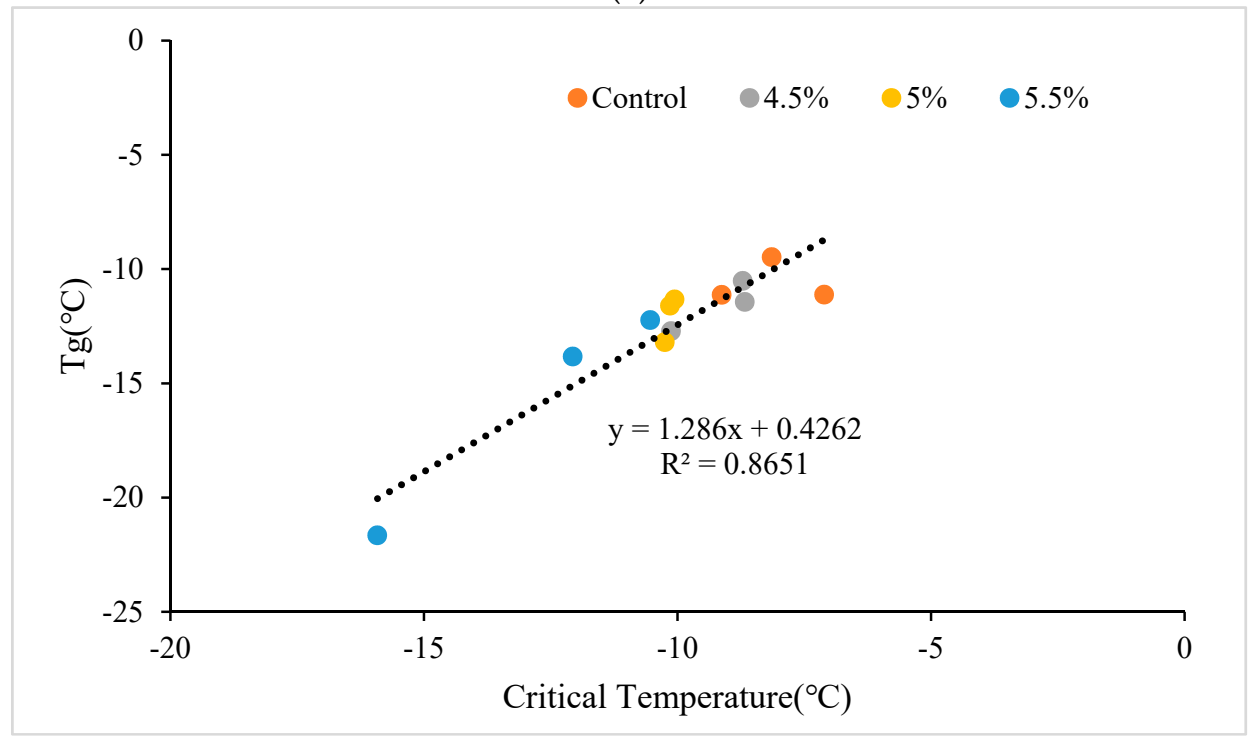

(b)

Figure 7. The relationship between critical temperature and $\mathrm{T}_{g}$ (a) different binder sources. (b) different content of SBS.

\subsubsection{The Glass Transition Temperature of Asphalt with Different Aging Degrees}

In order to further explore the change trend of the $\mathrm{T}_{g}$ of the asphalt binders under different aging degrees, the different aging states of three kinds of base asphalt and SBS modified asphalt with 5\% SBS were analyzed.

The glass transition temperature of three kinds of base asphalt in different aging states is shown in Figure 8. The glass transition temperature of unaged, RTFO and PAV state asphalt rose with the deepening of aging degree. Meanwhile, the glass transition temperature of the B70 and C90 asphalts from the same source decreased with the increase in grade. 


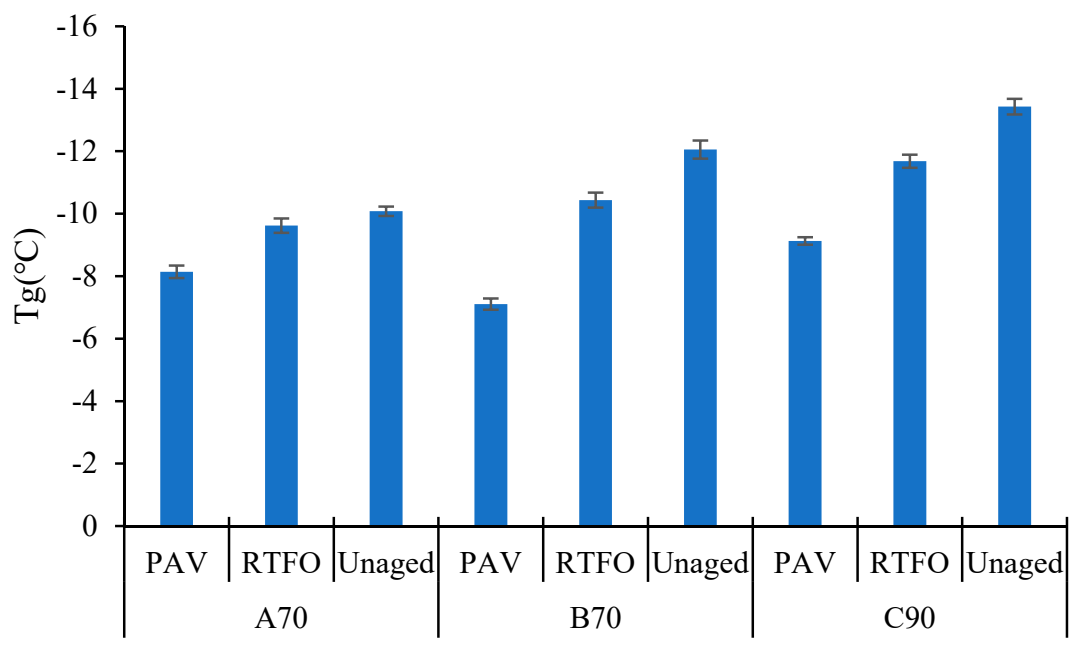

Types of Asphalt Binders

(a)

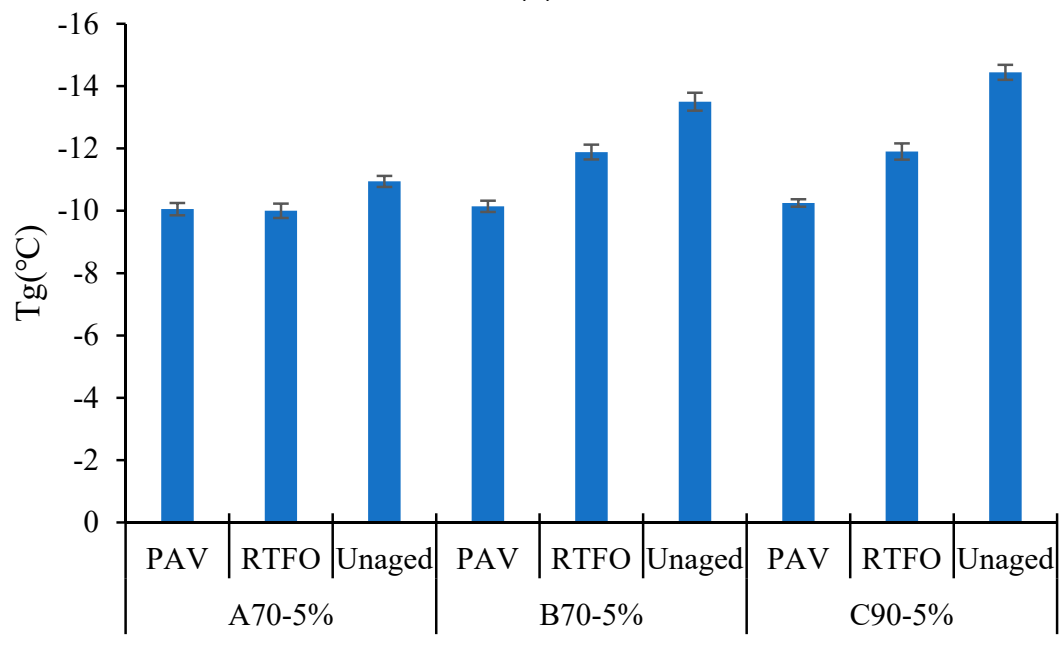

Types of Asphalt Binders

(b)

Figure 8. The $\mathrm{T}_{g}$ of binders at different aging states (a) base binder (b) SBS modified binder.

The glass transition temperatures of the three asphalt sources, with the addition of $5 \%$ SBS for different aging states, are shown Figure 8. The glass transition temperature of the modified asphalt in unaged, RTFO and PAV state rose with the increase in aging degree. At the same time, for the same source of asphalt in the B70 and C90 binders, the glass transition temperature at the same degree of aging decreased with the increase in grade.

In order to further verify the applicability of the glass transition temperature obtained by this method, the relationship between the glass transition temperature and the critical temperature of the corresponding asphalt under different aging conditions was established. As shown in Figure 9, the correlation coefficient $R=0.879$, between the critical temperatures of the three base asphalts and their glass transition temperatures, is greater than 0.666 (95\% confidence level, 7 degree of freedom), indicating that there was a significant correlation. Therefore, it is reasonable to use $\mathrm{T}_{g}$ to evaluate the low temperature performance of base asphalt in different aging states. It could be seen from Figure $9 \mathrm{~b}$ that the distribution range of the critical temperature and the $\mathrm{T}_{g}$ of different aging states were clear and significant, which could well characterize the low temperature performance of asphalt. 


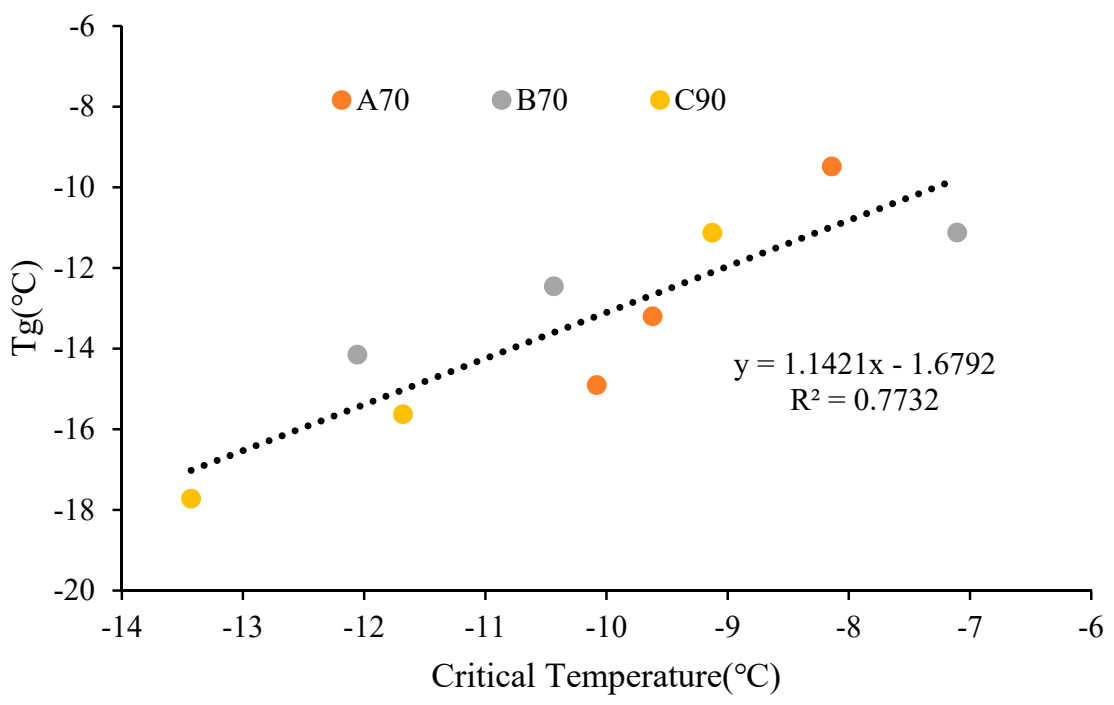

(a)

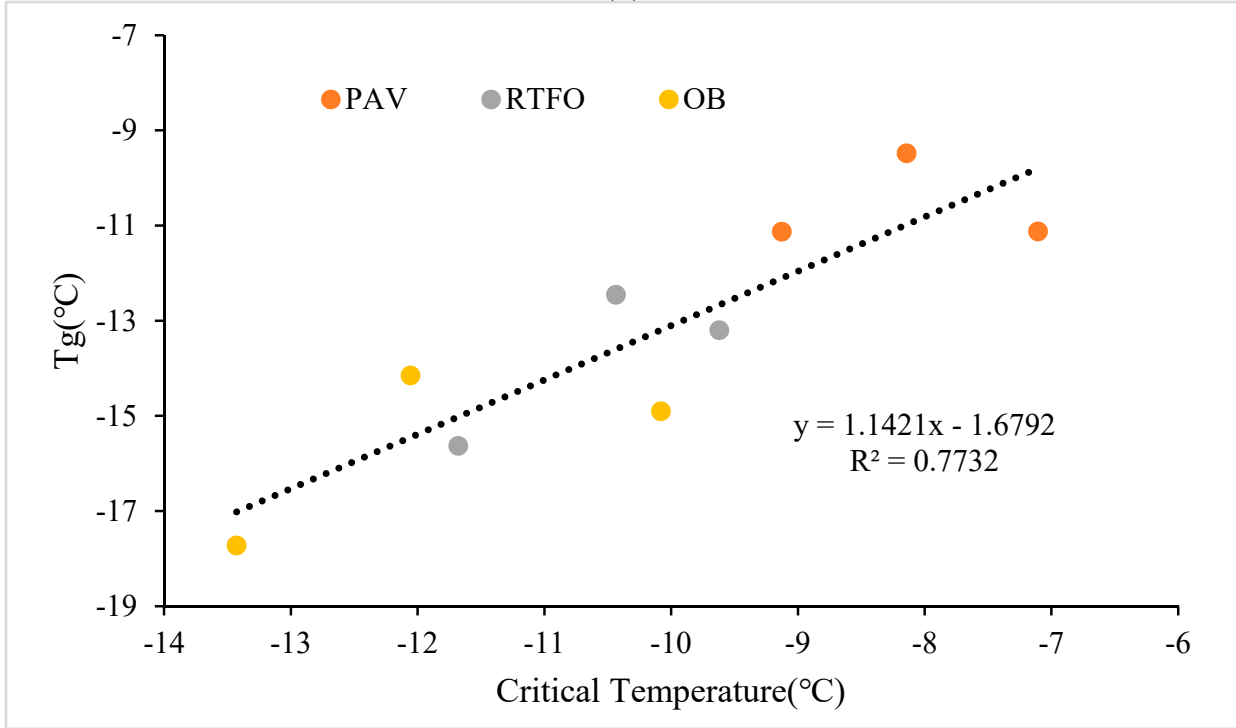

(b)

Figure 9. The relationship between critical temperature and $\mathrm{T}_{g}$. (a) base binders. (b) different aging states.

The correlation coefficient $\mathrm{R}=0.934$, between the critical temperature and $\mathrm{T}_{g}$ in different aging conditions for asphalt modified with the addition of 5\% SBS, was greater than 0.666 ( $95 \%$ confidence level, 7 degree of freedom). The result showed that the critical temperature of SBS asphalt modified with 5\% SBS content had a significant correlation with $\mathrm{T}_{g}$. At the same time, it could also be seen, from Figure 10, that the aging state had a great impact on the low temperature performance of the SBS modified asphalt. With the increase in the degree of aging, the $\mathrm{T}_{g}$ and critical temperature of SBS modified asphalt rose. The influence of aging degree on different asphalt sources was also very different. For A70 asphalt, the change between its critical temperature and $\mathrm{T}_{g}$, with the increase in the degree of aging, was little. For the C 90 asphalt, the different degrees of aging had a great influence on it, which made the critical temperature and $\mathrm{T}_{g}$ change greatly. The reason was mainly due to the different content of the components in the asphalt, which made it sensitive to the aging effect of different causes. 


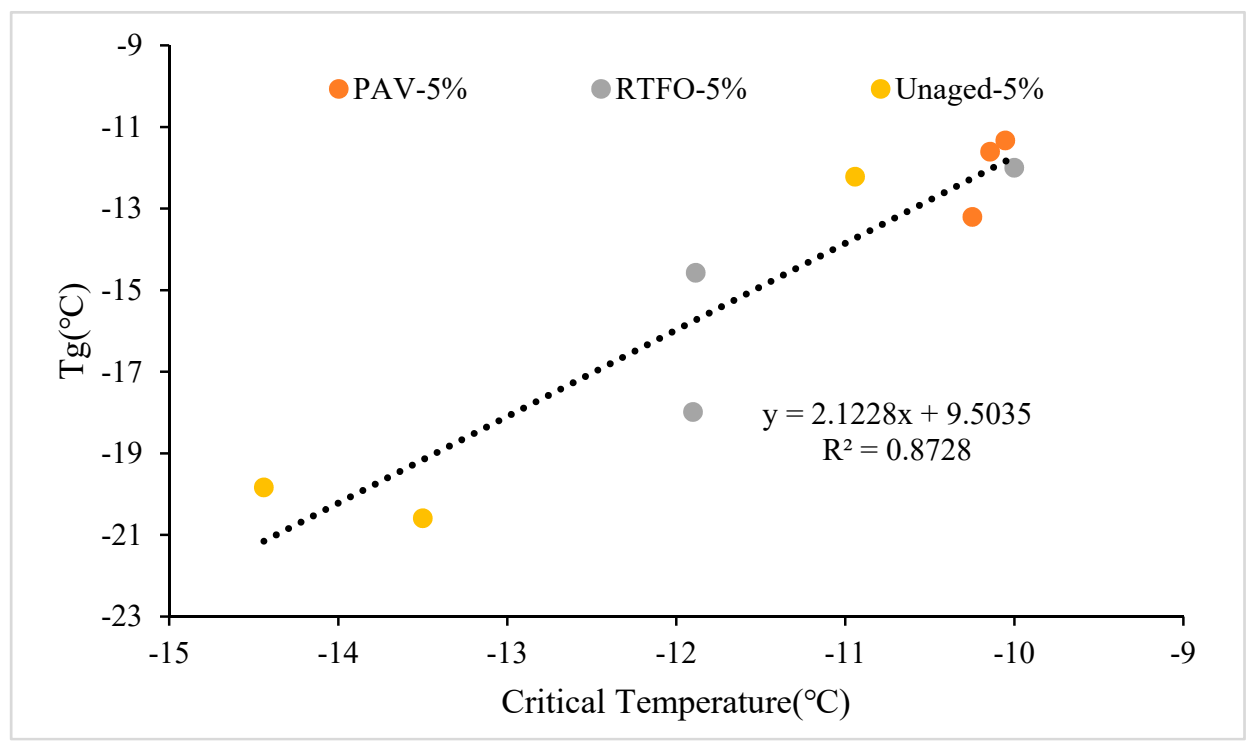

Figure 10. The relationship between critical temperature and $\mathrm{T}_{g}$ for SBS modified binder at different aging states.

\section{Conclusions}

The purpose of this study was to establish the relationship between the DSR results and BBR results of binders, and to find a rapid and accurate method to evaluate the low temperature performance of binders. The conclusions are as follows:

(1) The DSR device could be used to characterize the rheological properties of asphalt binders at different temperatures, which would be a potential for low temperature performance evaluation.

(2) A new method for evaluating the low temperature properties of asphalt was proposed. The glass transition temperature of base asphalt and SBS modified asphalt was determined by the viscoelastic parameters of the master curve and the WLF equation coefficients. By establishing a relationship with the critical temperature of asphalt, the effectiveness of the method developed in this paper was verified.

(3) The advantage of this method was the ability to use DSR test for the rapid evaluation of the low temperature performance of asphalt, which could save testing materials and time.

(4) The glass transition temperature of SBS modified asphalt was closely related to aging degree, asphalt source and SBS content. This was mainly due to the different sensitivity of asphalts from different sources, to aging.

Author Contributions: Conceptualization, T.W. and X.W.; methodology, D.Z.; software, H.S.; validation, Z.C.; formal analysis, Z.C.; investigation, Z.C.; resources, T.W.; data curation, T.W.; writingoriginal draft preparation, T.W.; writing-review and editing, Z.C.; project administration, Z.C.; funding acquisition, Z.C. All authors have read and agreed to the published version of the manuscript.

Funding: This research was funded by Tianjin Transportation Technology Development Plan Project (2019B-25), Shanghai Science and Technology Committee (Grant No. 20dz1202100) and the Fundamental Research Funds for the Central Universities (No. 2021RC209).

Institutional Review Board Statement: Not applicable.

Informed Consent Statement: Not applicable.

Data Availability Statement: Not applicable.

Conflicts of Interest: The authors declare no conflict of interest. 


\section{References}

1. Hao, J.; Cao, P.; Liu, Z.; Wang, Z.; Xia, S. Developing of a SBS polymer modified bitumen to avoid low temperature cracks in the asphalt facing of a reservoir in a harsh climate region. Constr. Build. Mater. 2017, 150, 105-113. [CrossRef]

2. Kök, B.V.; Yilmaz, M.; Geçkil, A. Evaluation of Low-Temperature and Elastic Properties of Crumb Rubber-and SBS-Modified Bitumen and Mixtures. J. Mater. Civ. Eng. 2013, 25, 257-265. [CrossRef]

3. Fu, L.; Xu, L. Application of Dynamic Shear and Bending Beam Rheometer Evaluation of Asphalt Performance. J. Petrochem. Univ. 2003, 16, 27-30.

4. Wang, T.; Xiao, F.; Amirkhanian, S.; Huang, W.; Zheng, M. A review on low temperature performances of rubberized asphalt materials. Constr. Build. Mater. 2017, 145, 483-505. [CrossRef]

5. Wang, T.; Xiao, F.; Zhu, X.; Huang, B.; Wang, J.; Amirkhanian, S. Energy consumption and environmental impact of rubberized asphalt pavement. J. Clean. Prod. 2018, 180, 139-158. [CrossRef]

6. Riccardi, C.; Cannone Falchetto, A.; Wang, D.; Wistuba, M.P. Effect of cooling medium on low-temperature properties of asphalt binder. Road Mater. Pavement Des. 2017, 18 (Suppl. 4), 234-255. [CrossRef]

7. Lu, X.; Uhlback, P.; Soenen, H. Rheological testing of bitumen at low temperatures with 4-mm DSR. In Proceedings of the 8th RILEM International Symposium on Testing and Characterization of Sustainable and Innovative Bituminous Materials, Ancona, Italy, 7-9 October 2015; Springer: Dordrecht, The Netherlands, 2016; pp. 643-653.

8. Büchner, J.; Wistuba, M.P.; Remmler, T.; Wang, D. On low temperature binder testing using DSR 4 mm geometry. Mater. Struct. 2019, 52, 1-11. [CrossRef]

9. Filonzi, A.; Lee, S.K.; Ferreira, W.; Hajj, R.; Bhasin, A. A micro-extraction method for use with 4 mm plate geometry in the Dynamic Shear Rheometer to evaluate asphalt binder rheology. Constr. Build. Mater. 2020, 252, 119024. [CrossRef]

10. Xiao, F.; Wang, T.; Hou, X.; Yuan, J.; Jiang, C.; Luo, Y. Waterproof and Antiscour Properties of Asphalt-Based Composite Seals for Airfield Base Layer. J. Mater. Civ. Eng. 2020, 32, 04019328. [CrossRef]

11. Soliman, H.; Shalaby, A.; Kavanagh, L. Performance evaluation of joint and crack sealants in cold climates using DSR and BBR tests. J. Mater. Civ. Eng. 2008, 20, 470-477. [CrossRef]

12. Kai, C.; Wenyuan, X.; Dan, C.; Huimin, F. High-and low-temperature properties and thermal stability of silica fume/SBS composite-modified asphalt mortar. Adv. Mater. Sci. Eng. 2018, 2018, 1317436. [CrossRef]

13. Laukkanen, O.V.; Soenen, H.; Winter, H.H.; Seppälä, J. Low-temperature rheological and morphological characterization of SBS modified bitumen. Constr. Build. Mater. 2018, 179, 348-359. [CrossRef]

14. Hou, X.; Xiao, F.; Guo, R.; Xiang, Q.; Wang, T.; Wang, J. Application of spectrophotometry on detecting asphalt content of emulsified asphalt. J. Clean. Prod. 2019, 215, 626-633. [CrossRef]

15. Khong, T.D.; Malhotra, S.L.; Blanchard, L.P. A study of the glass transition temperature of asphalts and their viscosity. Rheol. Acta 1978, 17, 654-662. [CrossRef]

16. Kriz, P.; Stastna, J.; Zanzotto, L. Glass transition and phase stability in asphalt binders. Road Mater. Pavement Des. 2008, 9 (Suppl. 1), 37-65. [CrossRef]

17. Wang, T.; Wang, J.; Hou, X.; Xiao, F. Effects of SARA fractions on low temperature properties of asphalt binders. Road Mater. Pavement Des. 2021, 22, 539-556. [CrossRef]

18. Masson, J.F.; Polomark, G.M. Bitumen microstructure by modulated differential scanning calorimetry. Thermochim. Acta 2001, 374, 105-114. [CrossRef]

19. Wada, Y.; Hirose, H. Glass transition phenomena and rheological properties of petroleum asphalt. J. Physical Soc. Jpn. 1960, 15, 1885-1894. [CrossRef]

20. Ghavibazoo, A.; Abdelrahman, M. Effect of crumb rubber dissolution on low-temperature performance and aging of asphaltrubber binder. Transp. Res. Rec. 2014, 2445, 47-55. [CrossRef]

21. Liu, J.; Sun, Y.; Wang, W.; Chen, J. Using the viscoelastic parameters to estimate the glass transition temperature of asphalt binders Constr. and Build. Mater. 2017, 153, 908-917. [CrossRef]

22. Zhiqiang, C.; Polaczyk Pawel Andrzej, Z.D. A method for determining impact locking point of asphalt mixtures based on dynamic response. J. Cent. South. Univ. (Sci. Technol.) 2021, 52, 2232-2245.

23. Kriz, P.; Stastna, J.; Zanzotto, L. Physical aging in semi-crystalline asphalt binders. Asph. Paving Technol. Proc. 2008, 77, 795.

24. Sun, Y.; Huang, B.; Chen, J.; Jia, X.; Ding, Y. Characterizing rheological behavior of asphalt binder over a complete range of pavement service loading frequency and temperature. Constr. Build. Mater. 2016, 123, 661-672. [CrossRef]

25. Liu, S.; Cao, W.; Shang, S.; Qi, H.; Fang, J. Analysis and application of relationships between low-temperature rheological performance parameters of asphalt binders. Constr. Build. Mater. 2010, 24, 471-478. [CrossRef]

26. Cheng, Z.; Jia, X.; Jiang, H.; Hu, W.; Huang, B. Quantification of impact compaction locking point for asphalt mixture. Constr. Build. Mater. 2021, 302, 124410. [CrossRef]

27. Asgharzadeh, S.M.; Tabatabaee, N.; Naderi, K.; Partl, M. An empirical model for modified bituminous binder master curves. Mater. Struct. 2013, 46, 1459-1471. [CrossRef] 
28. Pellinen, T.K.; Witczak, M.W.; Marasteanu, M.; Chehab, G.; Alavi, S.; Dongre, R. Stress dependent master curve construction for dynamic (complex) modulus. Asphalt paving technology: Association of asphalt paving technologists-proceedings of the technical sessions. Assoc. Asph. Paving Technol. 2002, 71, 281-309.

29. Huang, Y.; Liu, Z.H.; Li, S. Glass transition temperature calculation and low-temperature property analysis of asphalt. Mater. Rep. 2016, 30, 141-149. 